\title{
SAND2000.0627J
}

\section{Effect of Mg Ionization Efficiency on Performance of Npn AlGaN/GaN Heterojunction Bipolar Transistors}

C. Monier ${ }^{*}$ and S. J. Pearton

Department of Materials Science and Engineering, University of Florida, Gainesville, Florida 32611.

P. C. Chang and A. G. Baca

Sandia National Laboratories, Albuquerque, New Mexico 87185.

F. Ren

Department of Chemical Engineering, University of Florida, Gainesville, Florida 32611.

* : Current address at Sandia National Laboratories.

\begin{abstract}
A drift-diffusion transport model has been used to examine the performance capabilities of $\mathrm{AlGaN} / \mathrm{GaN} N p n$ heterojunction bipolar transistors (HBTs). The Gummel plot from the first GaN-based HBT structure recently demonstrated is adjusted with simulation by using experimental mobility and lifetime reported in the literature. Numerical results have been explored to study the effect of the p-type $\mathrm{Mg}$ doping and its incomplete ionization in the base. The high base resistance induced by the deep acceptor level is found to be the cause of limiting current gain values. Increasing the operating temperature of the device activates more carriers in the base. An improvement of the simulated current gain by a factor of 2 to 4 between 25 and $300^{\circ} \mathrm{C}$ agrees well with the reported experimental results. A preliminary analysis of high frequency characteristics indicates substantial progress of predicted $\mathrm{rf}$ performances by operating the device at higher temperature due to a reduced extrinsic base resistivity.
\end{abstract}

PACS Numbers: $\quad$ 85.30.Pq, 85.30.De, 61.72.V, 72.80.E 


\section{DISCLAIMER}

This report was prepared as an account of work sponsored by an agency of the United States Government. Neither the United States Government nor any agency thereof, nor any of their employees, make any warranty, express or implied, or assumes any legal liability or responsibility for the accuracy, completeness, or usefulness of any information, apparatus, product, or process disclosed, or represents that its use would not infringe privately owned rights. Reference herein to any specific commercial product, process, or service by trade name, trademark, manufacturer, or otherwise does not necessarily constitute or imply its endorsement, recommendation, or favoring by the United States Government or any agency thereof. The views and opinions of authors expressed herein do not necessarily state or reflect those of the United States Government or any agency thereof. 


\section{DISCLAIMER}

\section{Portions of this document may be illegible in electronic image products. Images are produced from the best available original document.}


In the past few years, much experimental and theoretical effort has been directed towards the fabrication and understanding of nitride-based devices. Interest in this material has been driven by advances in high-power, high-frequency transistors due to its high electron saturation velocity, high critical field, and high stability. AlGaN/GaN High Mobility Electron Transistors (HEMTs) with improved sheet carrier densities and two-dimensional mobilities have been reported [1-6]. Progress in nitride-based material quality and device processing has motivated the development of bipolar transistors which have demonstrated, in GaAs and InP systems, better linearity over the field effect transistor counterpart. Several groups have recently reported $N p n$ $\mathrm{AlGaN} / \mathrm{GaN}$ heterojunction bipolar transistors [7-9]. Initial DC current gain, $\beta$, as high as 3 was observed at room temperature. Poor conductivity of the $p$-type GaN base layer associated with low hole mobility is responsible for this limitation due to the high acceptor ionization energy $(\sim 170 \mathrm{meV})[8,9]$.

Enhanced Mg doping efficiency has been demonstrated through the use of $\mathrm{AlGaN} / \mathrm{GaN}$ superlattices but this would introduce issues related to the electron transport across the base [10]. Solutions implying piezoelectric effects associated with modulation-doped heterostructures have been also suggested to achieve higher free hole concentration in the base [11]. Improved DC characteristics have been obtained in the GaN-based HBTs at elevated temperature $\left(300^{\circ} \mathrm{C}\right)$ with current gain values up to $10[8,9]$. The impact of temperature is addressed in this paper by joining the experimental evidence with numerical investigation. There have been very few attempts at simulating HBTs in these materials [12]. In this work, parameters derived from simulating the existing Npn GaN-based HBT are used evaluating the acceptor ionization issue. The thermal influence on enhanced hole concentration and consequent lower base resistance is analyzed in terms of DC and rf performances through the use of the numerical approach. 
The typical structure consists of a $0.5 \mu \mathrm{m}$, Si-doped $\left(10^{17} \mathrm{~cm}^{-3}\right) \mathrm{GaN}$ collector followed by a $0.15-0.2 \mu \mathrm{m}, M g$-doped (free hole concentration $<1 \times 10^{18} \mathrm{~cm}^{-3}$ for a doping concentration in the $10^{20} \mathrm{~cm}^{-3}$ range) $\mathrm{GaN}$ base and a $0.1 \mu \mathrm{m}$, Si-doped $\left(5 \times 10^{17} \mathrm{~cm}^{-3}\right) \mathrm{Al}_{0.15} \mathrm{Ga}_{0.85} \mathrm{~N}$ emitter. The operation of the Npn GaN-based HBT was simulated by using a program based on the driftdiffusion model [13]. Performance analysis was achieved by self-consistent solution of the Poisson, carrier continuity and current density equations of a two-dimensional structure. Physical models incorporated in the simulation include carrier statistics and generation-recombination mechanisms. A typical conduction band offset ratio $\mathrm{Q}_{C}$ of 0.70 is considered to describe the energy band gap discontinuity at the emitter/base interface [4]. The specific contact resistances for both $n$ and $p$-type materials are also specified according to recent reports with improved characteristics [14-17]. The Gummel plot from the initial large area HBT previously demonstrated elsewhere $[8,9]$ is adjusted with simulation by using experimental minority carrier mobility and lifetime values resulting from careful analysis of data available in the literature [1820]. Note that measured Hall mobility values at room temperature are considerably lower than those extracted from a theoretical approach [18]. Since no systematic measurement of lifetime as a function of doping levels was reported, an interpolation process has been used for their value through the entire device structure. Calculations also account for incomplete impurity ionization in the $p$-type GaN base layer. The ionized acceptor impurity concentration is given by the classical Fermi-Dirac statistics with appropriate acceptor energy level $\mathrm{E}_{\mathrm{A}}$ and operating temperature $T$.

Figure 1 shows calculated Gummel plots in the common emitter configuration. The operating temperature is intentionally fixed at $25^{\circ} \mathrm{C}$. The initial doping concentration $\mathrm{N}_{\mathrm{A}}$ in the base layer is equal to $10^{20} \mathrm{~cm}^{-3}$ and several acceptor activation energies are considered through an arbitrary parameter $\mathrm{E}_{\mathrm{A}}$ to describe different incomplete ionization conditions. The $\mathrm{E}_{\mathrm{A}}$ 
parameter variation is used as a means of considering the effect of temperature changes. Because of the uncertainty related to minority carrier lifetime and mobility values and their strong dependence on the $\mathrm{GaN}$ material quality, a relative comparison between numerical results is considered to understand the various elements affecting the device performances. In each case, a turn-on voltage of approximately $3.0 \mathrm{~V}$ is observed due the wide energy band-gap $(\sim 3.85 \mathrm{eV})$ characterizing the ternary AlGaN emitter layer. No significant differences are observed with base-emitter voltage value $V_{B E}$ up to $3.5 \mathrm{~V}$, except that the base current $I_{B}$ is more sensitive to the free hole concentration and is always larger than the collector output $I_{C}$. As $V_{B E}$ increases, $I_{C}$ is strongly affected by the amount of ionized acceptors. Devices with poor $\mathrm{Mg}$ efficiency exhibit an $\mathrm{I}_{\mathrm{C}}$ output lower by one order of magnitude compared to devices with the highest activated doping species. A less dramatic variation is found for $I_{B}$ in the same $V_{B E}$ bias range. Therefore, current gain values higher than $\beta=1$ (when the crossing between $I_{C}$ and $I_{B}$ occurs) are produced at much lower $\mathrm{V}_{\mathrm{BE}}$ bias if more $\mathrm{Mg}$ acceptors are activated. This ability to generate $\mathrm{Mg}$ efficiencydependent current gain values is illustrated in Fig 2. The DC gain is shown as a function of $V_{B E}$ for the same previous set of activation energies. The dashed line crossing the graph corresponds to the case of unity current gain. Working HBTs with $\beta>1$ can be realized with moderate $V_{\mathrm{BE}}$ voltage when the free hole concentration is not too degraded. An increasing "threshold" voltage for gain higher than 1 is observed as the $\mathrm{Mg}$ activation is reduced. No amplification gain can ultimately be achieved unless an extremely high but unrealistic $\mathrm{V}_{\mathrm{BE}}$ bias is applied. These results are analyzed in terms of improved extrinsic base resistance. A highly resistive base layer induced by the deep $\mathrm{Mg}$ nature forces base current flowing directly to the collector, bypassing the base. These carriers are usually required to control the amount of the base-emitter bias, and the amount of electron injection from the emitter to the base. Hence, reducing the Mg efficiency in the base has a direct impact on the amount of current collected at the collector. A practical way of 
reproducing the $\mathrm{Mg}$ efficiency enhancement is to consider $\mathrm{AlGaN} / \mathrm{GaN}$ HBTs operating at higher temperature as suggested earlier $[8,9]$. Thermally activating more carriers in the GaN base reduces its resistivity. More carriers supplied by the base contact flow to the intrinsic base region and contribute to apply higher bias, inject more electrons and achieve higher gain as experimentally demonstrated by operating the device at $300^{\circ} \mathrm{C}[8,9]$. Figure 3 shows the simulated current gain plotted as a function of the collector current density for two distinct conditions of ionization efficiency that can describe device operations at respectively room temperature and $\mathrm{T}=300^{\circ} \mathrm{C}$. A normalized unit for $\beta$ has been chosen for a relative comparison. Although characteristics converge for high current density, an unrealistic $V_{\mathrm{BE}}$ bias would be required at room temperature operation. Differences are observed for lower densities. Calculations predict an improvement for $\beta$ by a factor of 2 to 4 which agrees well with experimental observations reported for the same range of output current density $\left(\sim 10 \mathrm{~A} / \mathrm{cm}^{2}\right)$. In these past results, the current gains were typically $\sim 3$ at room temperature and $\sim 10$ at $300^{\circ} \mathrm{C}$ (the latest is displayed in the inset of Fig.3).

In addition to DC current gain, the small signal gain $h_{2 l}$ and the unilateral power gain $U$ for small active areas have been calculated and plotted in Fig. 4 as a function of the frequency for the two previous $\mathrm{Mg}$ ionization efficiencies characterizing room temperature and high temperature $\left(\mathrm{T}=300^{\circ} \mathrm{C}\right)$ operating conditions. Simulated if performances are obtained by calculating conductances and capacitances between each pair of electrodes and the induced $S$ parameters at a given DC bias condition. The collector current density is fixed at the same value in both cases. Hence, only the base transit time among all the various charging/transit times is affected and the isolated effect of the base resistance can be addressed. The corresponding cutoff frequency, $f_{\mathrm{t}}$, and maximum oscillation frequency, $f_{\max }$, have been extrapolated as figures of merit for high-frequency characteristics. While $f_{\mathrm{t}}$ increases slightly over the temperature range 
due to a shorter base transit time, the $f_{\max }$ value dramatically improves by a factor of two. The $f_{\max }$ is usually optimized with regard to $f_{\mathrm{t}}$ but is also inversely proportional to the square root of the base resistance [21]. Again, results suggest that operating at higher temperature with an increased $\mathrm{Mg}$ doping efficiency significantly reduces the base resistivity for an improved $f_{\max }$ values. Note that $f_{\max }$ has been always found lower than $f_{\mathrm{t}}$. The problematic ionization efficiency of $\mathrm{Mg}$ acceptors also makes the realization of $p$-ohmic contacts with low resistance difficult. Predictions show that devices with ideally low base contact resistance exhibit $f_{\max }$ values as high as $f_{t}$ as seen in Fig. 4. These encouraging values are expected to increase, as issues related to defects and impurities are better understood and resolved.

In summary, the influence of the Mg ionization efficiency on the $N p n$ GaN-based HBT has been theoretically addressed. The highly resistive base layer induced by the deep $\mathrm{Mg}$ energy level forces base current to flow directly to the collector. Operating at higher temperature activates more carriers in the $\mathrm{GaN}$ base and reduces its resistivity. More carriers flow into the intrinsic base region and contribute to a better carrier injection, producing higher DC current gain. The effect of the thermally improved acceptor efficiency has been analyzed in terms of high frequency performance. Preliminary simulated rf results show dramatic improvement of the maximum oscillation frequency $f_{\max }$. Further enhancements can be pursued by considering compositional grading for improved base transport to realize good current gain as well as piezoelectrically induced free holes in the extrinsic $p$-type region to reduce the base resistance.

The work at UF is partially supported by ONR grant N00014-98-1-0204 (J.C. Zolper) and a DARPA/EPRI Grant MDA-972-98-1-0006 (D. Radack/J. Melcher). Sandia is a multiprogram laboratory operated by Sandia Corporation, a Lockheed-Martin company, for the US Department of Energy under Contract N ${ }^{\circ}$ DE-AC04-94-AL-85000. 


\section{References:}

[1] M. J. Murphy, K. Chu, H. Wu, W. Yeo, W. J. Schaff, O. Ambacher, L. F. Eastman, T. J. Eutsis, J. Silcox, R. Dimitrov, and M. Stutzmann, Appl. Phys. Lett. 75, 3653 (1999)

[2] R. Li, S. J. Cai, L. Wong, Y. chen, K. L. Wang, R. P. Smith, S. C. Martin, K. S. Boutros, and J. M. Redwing, IEEE Electron Device Lett. 20, 323 (1999)

[3] H. Morkoc, R. Cingolani, and B. Gil, Solid-State Electron. 43, 1753 (1999)

[4] O. Ambacher, J. Smart, J. R. Shealy, N. G. Weimann, K. Chu, M. Murphy, W. J. Schaff, L. F. Eastman, R. Dimitrov, L. Wittmer, M. Stutzmann, W. Rieger, and J. Hilsenbeck, J. Appl. Phys 85, 3222 (1999)

[5] I. P. Smorchkova, C. R. Elsass, J. P. Ibbetson, R. Ventury, B. Heying, P. Fini, E. Haus, S. P. DenBaars, J. S. Speck, and U. K. Mishra, J. Appl. Phys 86, 4520 (1999)

[6] R. Gaska, M. S. Shur, A. D. Bykhovski, A. O. Orlov, and G. L. Snider, Appl. Phys. Lett. 74, 287 (1999)

[7] L. S. McCarthy, P. Kozodoy, M. J. W. Rodwell, S. P. DenBaars, and U. K. Mishra, IEEE Electron Device Lett. 20, 277 (1999)

[8] F. Ren, C. R. Abernathy, J. M. Van Hove, P. P. Chow, R. Hickman, J. J. Klaassen, R. F. Kopf, H. Cho, K. B. Jung, J. R. Laroche, R. G. Wilson, J. Han, R. J. Shul, A. G. Baca, and S. J. Pearton, MRS Internet J. Nitride Semicond. Res. 3, 41 (1998)

[9] J. Han, A. G. Baca, R. J. Shul, C. G. Willison, L. Zhang, F. Ren, A. P. Zhang, G. T. Dang, S. M. Donovan, X. C. Cao, H. Cho, K. B. Jung, C. R. Abernathy, S. J. Pearton, and R. G. Wilson, Appl. Phys. Lett. 74, 2702 (1999)

[10] P. Kozodoy, M. Hansen, S. P. DenBaars, and U. K. Mishra, Appl. Phys. Lett. 74, 3681 (1999)

[11] L. Hsu, and W. Walukiewicz, Appl. Phys. Lett. 74, 2405 (1999)

[12] S-Y. Chiu, A. F. M. Anwar, and S. Wu, MRS Internet J. Nitride Semicond. Res. 4S1, G6.7 (1999)

[13] Atlas, Silvaco International (1999)

[14] S. J. Pearton, J. C. Zolper,R. J. Shul , and F. Ren, J. Appl. Phys 86, 1 (1999)

[15] Z. Fan, S. N. Mohammad, W. Kim, O. Atkas, A. E. Botchkarev, and H Morkoc, Appl. Phys. Lett. 68, 1672 (1996)

[16] J-S. Jang, I-S. Chang,H-K. Kim, T-Y. Seong, S. Lee, and S-J. Park, Appl. Phys. Lett. 74, 70 (1999)

[17] M. Suzuki, T. Kawakami, T. Arai, S. Kobayashi, Y. Koide, T. Uemura, N. Shibata, and M. Murakami, Appl. Phys. Lett. 74, 275 (1999)

[18] D. L. Rode, and D. K. Gaskill, Appl. Phys. Lett. 66, 1972 (1995)

[19] Z. Z. Bandic, P. M. Bridger, E. C. Piquette, and T. C. McGill, Appl. Phys. Lett. 73, 3276 (1998)

[20] Z. Z. Bandic, P. M. Bridger, E. C. Piquette, and T. C. McGill, Appl. Phys. Lett. 72, 3166 (1998)

[21] W. Liu in Handbook of III-V Heterojunction Bipolar Transistors (Wiley-Interscience, New York, 1998) 


\section{Table of contents}

Figure 1: Calculated base and collector current output as a function of the base-emitter voltage for large area $N p n$ AlGaN/GaN HBT for several values of activation energy $\mathrm{E}_{\mathrm{A}}$. The doping concentration in the based is fixed to $10^{20} \mathrm{~cm}^{-3}$. Arrows identify the crossing between $\mathrm{I}_{C}$ and $\mathrm{I}_{B}$ associated with current gain higher than 1 .

Figure 2: Current gain $\beta$ extracted from simulation by considering various activation energies. The horizontal dashed line represents the case of unity current gain.

Figure 3: Normalized theoretical current gain $\beta$ as a function of the collector current density for two conditions of ionization efficiency related to low temperature $\left(\sim 25^{\circ} \mathrm{C}\right)$ and higher temperature $\left(\sim 300^{\circ} \mathrm{C}\right)$. The inset displays the improved experimental Gummel plot measured at $\mathrm{T} \sim 300^{\circ} \mathrm{C}$.

Figure 4: Simulated small-signal performances for $\mathrm{Npn}$ AlGaN/GaN HBTs corresponding to low temperature $\left(-25^{\circ} \mathrm{C}\right)$ and elevated temperature $\left(\sim 300^{\circ} \mathrm{C}\right)$ conditions. Predictions for ideal devices with optimized base contact resistance are also displayed. The cut-off frequency $f_{t}$ is taken where the current gain $h 21$ reaches unity. The maximum oscillation frequency $f_{\max }$ is taken where the unilateral power gain $U$ reaches unity. 


\section{Figure 1:}

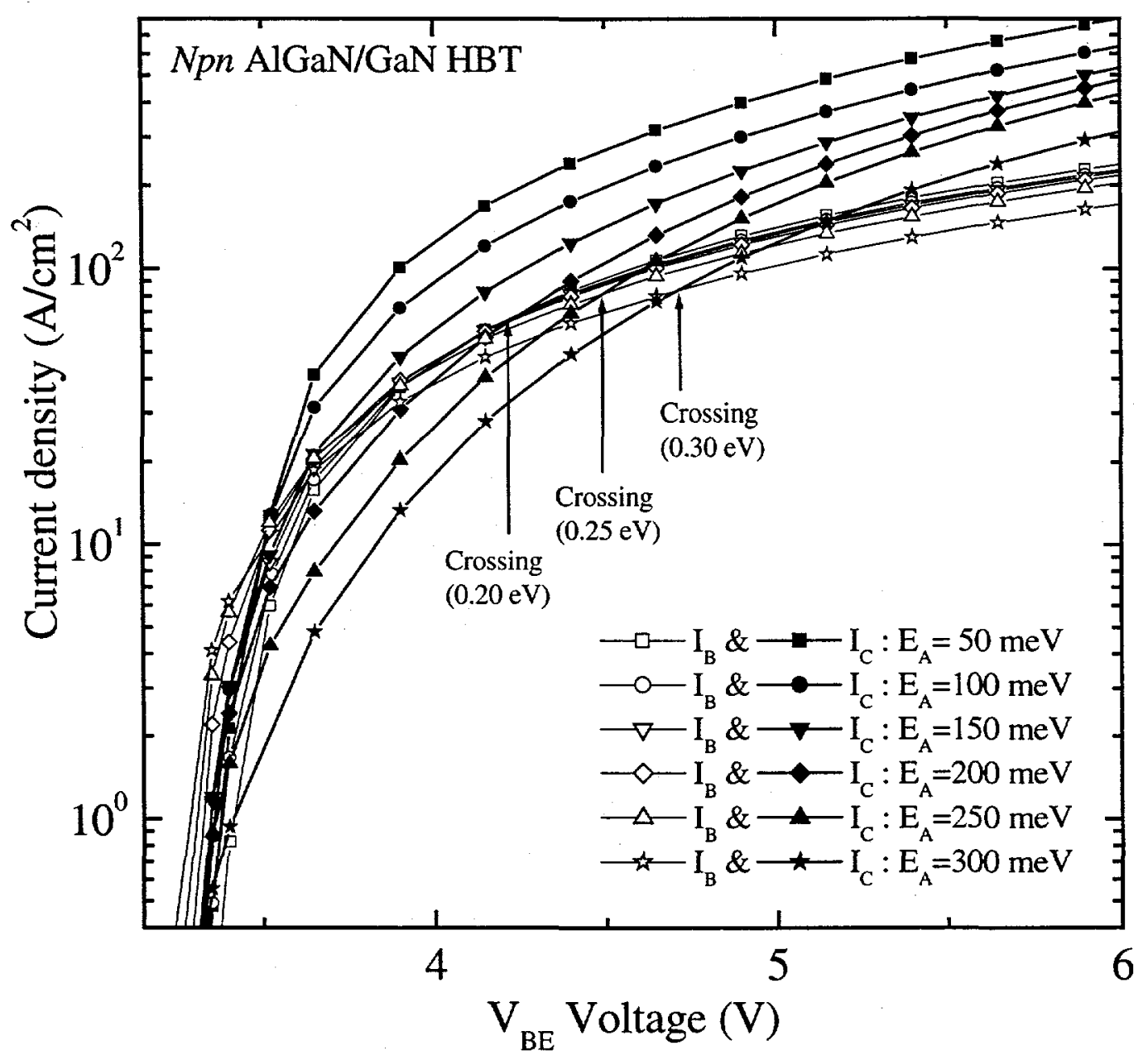


Figure 2:

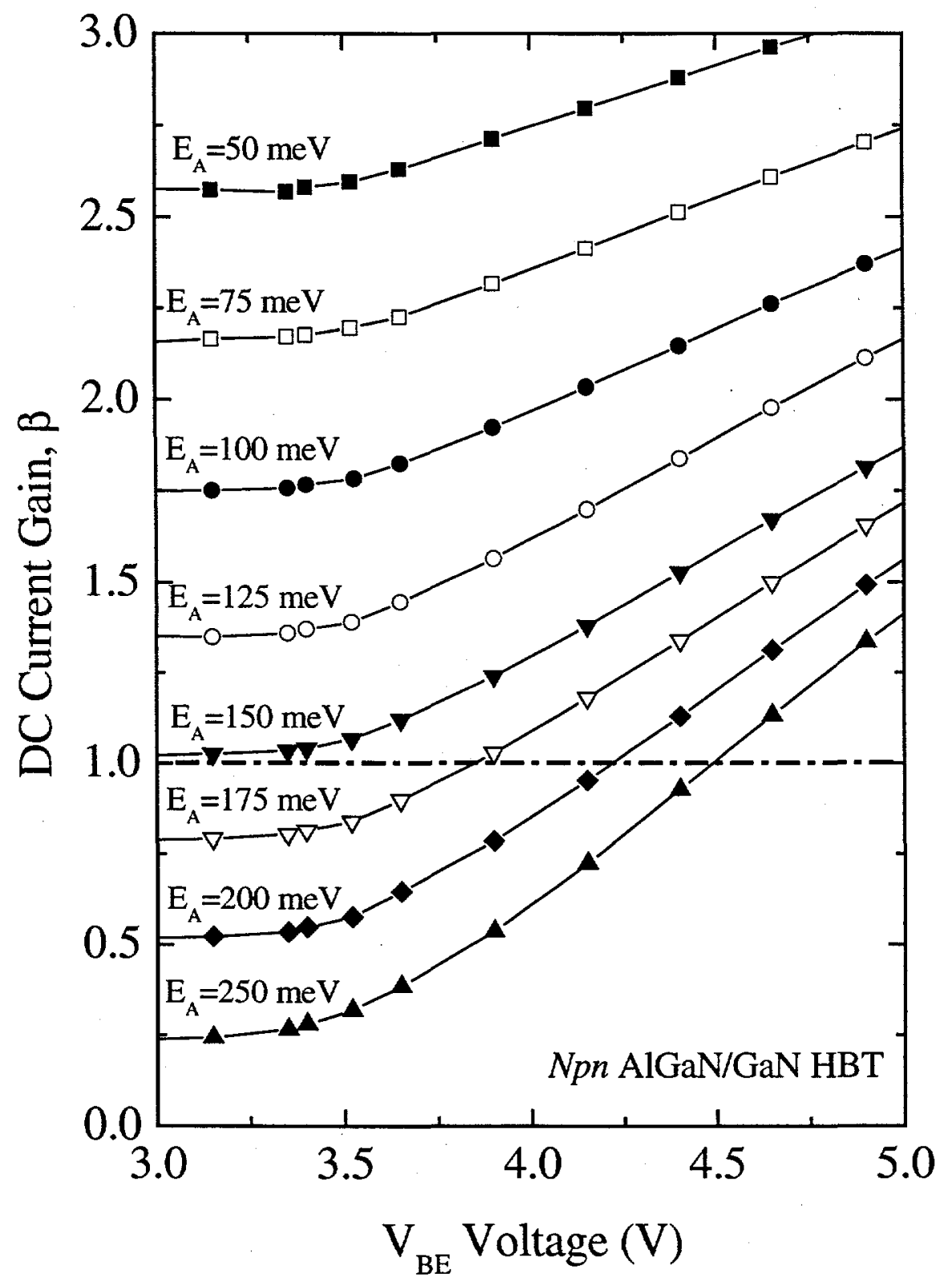




\section{Figure 3:}

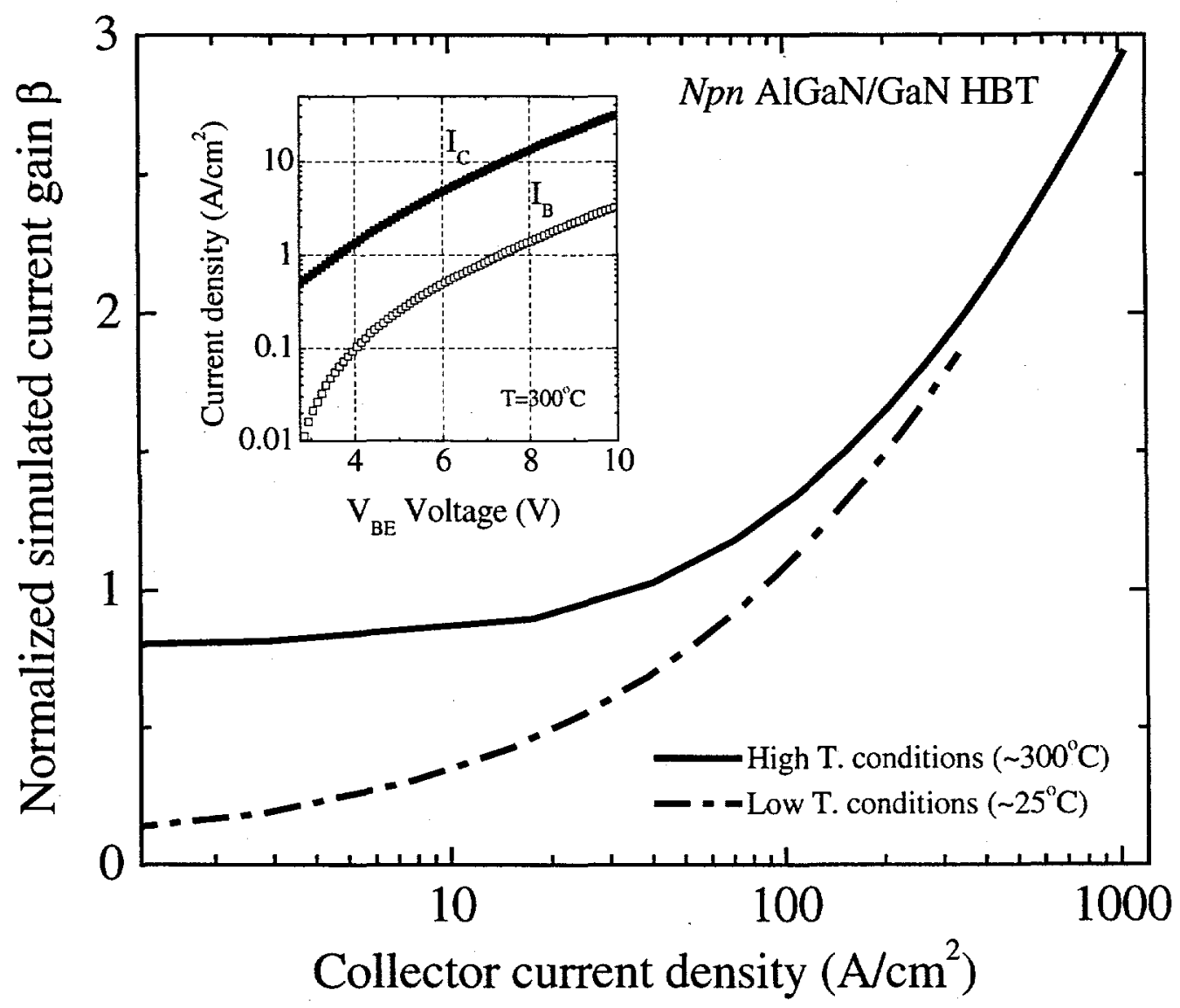




\section{Figure 4:}

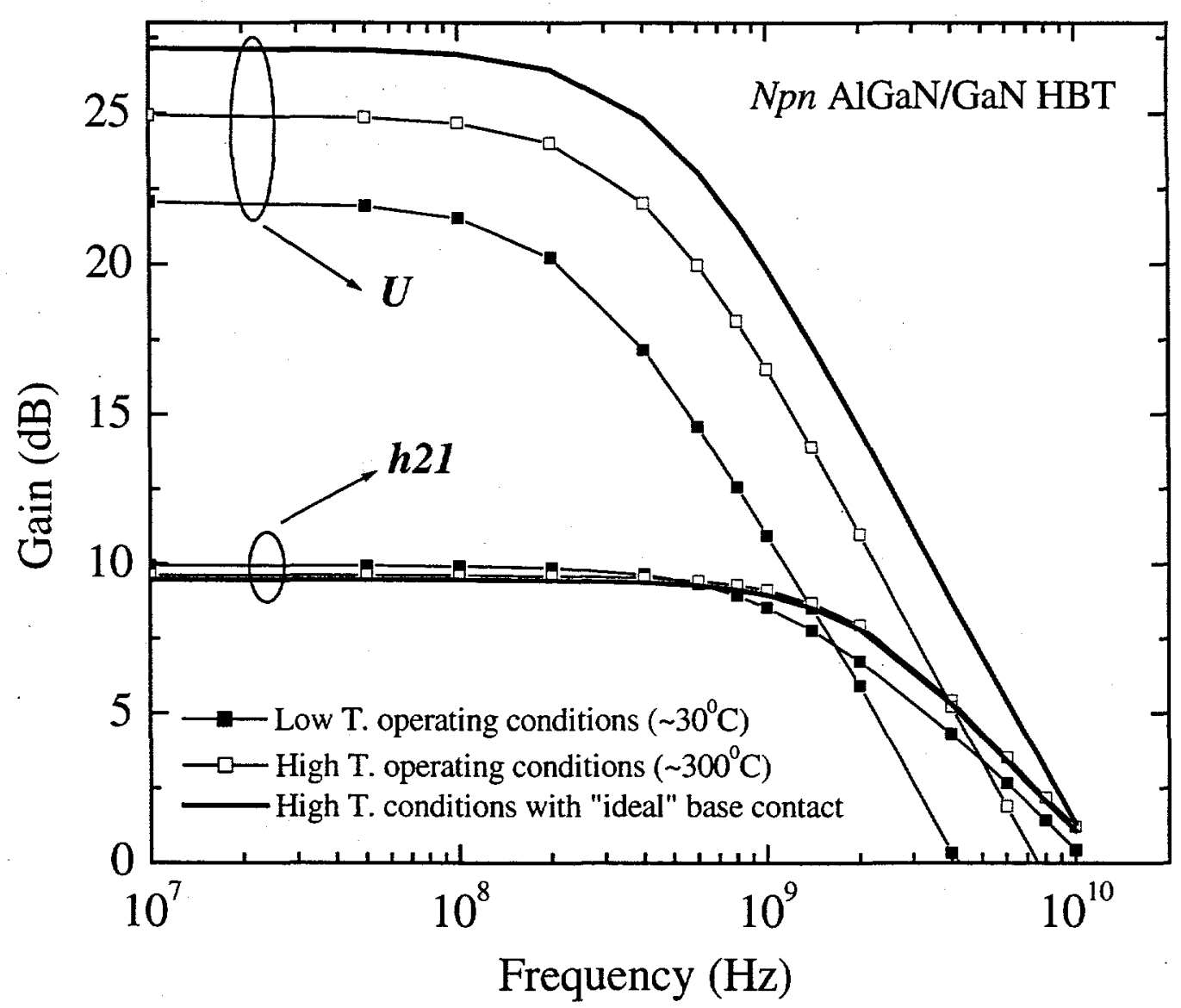

